'A Jamiy: Jurnal Bahasa dan Sastra Arab

Available Online at http://journal.umgo.ac.id/index.php/AJamiy

Volume 9, No. 2, September 2020, 265-284

DOI: http://dx.doi.org/10.31314/ajamiy.9.2.265-284.2020

\title{
DIAKRITIK AL-QUR'AN MENURUT PREFERENSI ABU DAWUD
}

\author{
Ibnu Rawandhy N. Hula ${ }^{1}$, Berti Arsyad ${ }^{2}$ \\ 1. IAIN Sultan Amai Gorontalo, Indonesia \\ 2. Universitas Muhammadiyah Gorontalo, Indonesia
}

Email: 1. Ibnurawandi@iaingorontalo.ac.id 2. bertiarsyad@umgo.ac.id

Diterima:2020-09-17 ; Disetujui: 2020-09-26 ; Dipublikasikan: 2020-09-26

\section{Abstract:}

This research examines the diacritic marks of al-Quran, which focuses on the punctuation aspect, both syakal and nuqt according to Abu Däwüd Sulaimän bin Najjäh. The research is library research wich sourced from opus of usūl al-ḍabt wa kaifiyatuhu 'ala jihhah alikhtisăar. The results show that Abü Däwüd's preference found on several things : 1) The

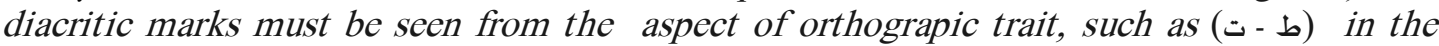
word (بسطت), the letter (ط) without adding absence of vowels because it itbăq, 2 The

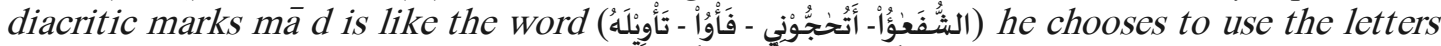

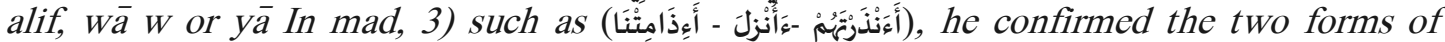
hamzah, according to the qira school of thought 'at al-Kisā'i and al-Farrā ', 4) Diacritic

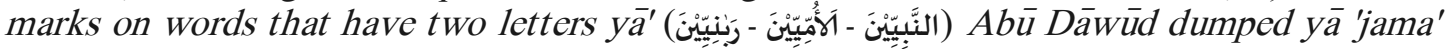

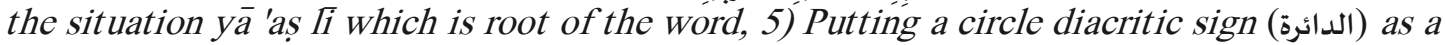
symbol ziyādah yā', which is not read (نباي - أفِاين) While, on the word (بائيد) which has two yā', Abū Dāwüd put absence of vowels on the first yā', as differentiator between yā 'așli and yā' zà idah.

\section{Keywords: Diacritics, Preference, Abū Dāwūd, ilmu al-Ḍabt.}

\begin{abstract}
Abstrak:
Penelitian ini mengkaji tentang diakritik al-Quran/al-dabt, yang menitik beratkan pada aspek tanda baca, baik syakal/harakat maupun titik/nuqt menurut preferensi Abü Dāwüd Sulaimān bin Najjăh. Jenis penelitian ini adalah penelitian kepustakaan yang bersumber dari karya ușūl al-dabt wa kaifiyatuhu 'ala jihhah al-ikhtisăar. Hasil penelitian menunjukkan bahwa, preferensi Abu Dawud terdapat pada beberapa hal: 1) Tanda diakritik harus dilihat dari aspek sifăt al-ḥurūf seperti (ط) pada kata (بسطت), huruf (b) tanpa dibubuhi sukun

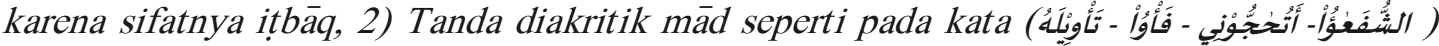
beliau cenderung memilih pendapat menghilangkan huruf alif, wāw maupun yā' pada mad,

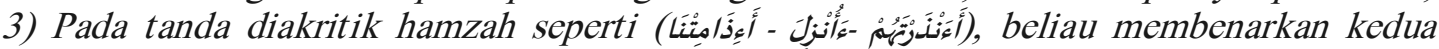
bentuk penulisan hamzah, sesuai dengan madzhab qirā'at al-Kisā'i dan al-Farrā', 4) Tanda

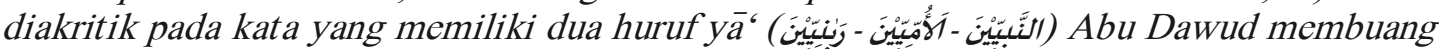
yā' jama' ketimbang yă', ași yang menjadi akar kata, 5) Memberi tanda diakritik berbentuk lingkaran (الدائرة) sebagai simbol ziyādah yā', yang tidak dibaca (نبإي - أَفِين) sedangkan pada kata (بأييد) yang memiliki dua yā', Abū Dawud meletakkan tanda sukun pada yā' pertama, sebagai pembeda antara yā' așli dan yā'zāidah.
\end{abstract}

Kata Kunci: Diakritik, Preferensi, Abū Dāwūd, ilmu al-Dabt.

\section{A. Pendahuluan}

Tulisan/rasm al-Quran sejak masa Rasulullah hingga masa khalifah Usman bin ‘Affan pada hakekatnya masih bersih dari titik dan syakal (غير منطوقة ولا مشكولة),

\section{'A Jami Jurnal Bahasa dan Sastra Arab}


bahkan bentuk rasm-nya masih sangat kaku berjenis script kufic ${ }^{1}$ yang bertahan sampai 40 tahun setelah nabi wafat. Pada perkembangan selanjutnya, keberadaan tulisan alQuran sepertinya rentan menimbulkan ikhtilaf di kalangan masyarakat Islam pada saat itu, mengingat ajaran Islam yang bersumber dari al-Quran semakin hari semakin meluas, disamping itu faktor lokalitas daerah dan lahjah-nya orang-orang ' Ajam $^{2}$ menimbulkan efek lahn al-qira' $a h^{3}$ yang tidak bisa terhindarkan.

Terhadap fenomena ini, muncullah ulama-ulama hebat di masa tabi'in, seperti Abū Aswad al-Du'āi (w 69 H), Ỵahyā bin Ya'mar (w. 90 H), Naṣr bin ‘Āṣim al-Lais「 (w.90 H) dan Khalil Ahmad al-Farahidi (w. 179 H) yang sangat gelisah melihat bacaan al-Quran yang berbeda-beda antara satu dengan yang lainnya, sehingga al-Quran dalam wujud tulisan (rasm) perlu diberikan penanda khusus agar bentuk huruf dan bunyinya antara satu dengan yang lainnya memiliki penciri dan pembeda. Dari merekalah muncullah embrio ilmu yang dikenal dengan al-dabt atau ilmu diakritik (diacritical marks) $^{4}$ yang berfungsi sebagai petunjuk dan pembeda bacaan dengan tanda-tanda khusus, sekaligus membantu agar lisan tidak salah dalam membaca alQur'an. ${ }^{5}$

Term diakritik jika merujuk pada kamus bahasa Indonesia, didefinisikan sebagai tanda tambahan pada huruf yang sedikit banyak mengubah nilai fonetis huruf. ${ }^{6}$ Dalam kajian ilmu-ilmu al-Quran kekinian juga menyebutkan bahwa ilmu yang membahas tentang tanda diakritik al-Qur'an disebut dengan ilmu al-ḍabt, atau juga disebut dengan ilmu naqt wa syakal, yang secara aplikatif tidak lepas dari ilmu rasm mushaf, karena wujud ortografi $\mathrm{Arab}^{7}$ antara huruf dan tanda baca (diakritik) berfungsi saling melengkapi sehingga memudahkan seseorang untuk membaca al-Qur'an.

\footnotetext{
${ }^{1}$ Salwa Ibraheem Tawfeeq Al-Amin, "The Origin of the Kufic Script," Magazine of historical studies and archaeology دراسات في التاريخ والاثار no. 53 (2016): 705-719.

2 Ali Audah, Konkordansi Quran : Panduan Dalam Mencari Ayat Al-Quran, Litera Antar Nusa, vol. 2 (Bogor: Pustaka Lintera Antar Nusa, 1997) Kata 'Ajam diabadikan dalam al-Quran sebanyak 3

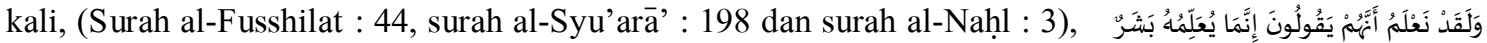

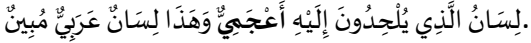

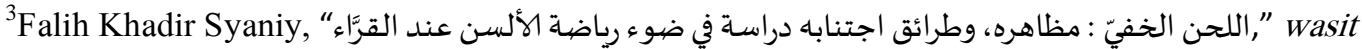
journal for humanities

${ }^{4}$ Samuel Green, "The Different Arabic Versions of the Qur'an," Answering Islam. Last modified March 7 (2016).

${ }^{5}$ Sya'bān Muhammad Ismā'il, Rasm Al-Muṣhaf Wa Dabtuhu Baina Al-Tauqifī Wa Al-Istilahāt Al-Hadiṣah (Al-Qāhirah: Dār al-Salām, 2012), 89. 241.

${ }^{6}$ Pusat Bahasa, Kamus Bahasa Indonesia (Jakarta: Departemen Pendidikan Nasional, 2008),

${ }^{7}$ Ibnu Rawandhy Hula, "Genealogi Ortografi Arab (Sebuah Tinjauan Historis: Asal-Usul, Rumpun Bahasa Dan Rekaman Inskripsi)," A Jamiy: Jurnal Bahasa dan Sastra Arab 9, no. 1 (2020): h. $16-46$.
}

\section{'A Jami Jurnal Bahasa dan Sastra Arab}


Hisyami bin Yazid menyebutkan bahwa pentingnya ilmu diakritik al-Qur'an bertujuan untuk tiga hal, yakni: 1) menjaga bunyi huruf al-Quran supaya tetap dibaca seperti yang diajarkan oleh Rasulullah kepada para sahabatnya, 2) Untuk menyelamatkan umat manusia dari kesalahan dalam membaca al-Quran, dan 3) Untuk menghilangkan kesamaran bacaan antar satu huruf dengan huruf lainnya yang serupa bentuk, baik huruf hidup maupun huruf mati. ${ }^{8}$ Diakritik al-Qur'an termasuk cabang ilmu yang cukup rumit, karena al-Qur'an yang meliputi tulisan dan bacaan, memiliki karakteristik tersendiri dan berbeda dengan tulisan pada bahasa lain. Karakteristik tersebut terangkum pada: 1) Adanya rasm, yang merupakan batang tubuh huruf alQur'an), 2) Adanya syakal dan harakat, yang berfungsi sebagai pembeda bunyi bacaan vokal dan konsonan, 3) Adanya nuqat, yang berbentuk titik, sebagai simbol pembeda huruf yang berkemiripan bentuk, dan 4) tanda-tanda lain yang berkaitan dengan mulai dan berhentinya sebuah bacaan (alāmah al-waqaf wa al-ibtidā').

Masih banyak dari kita yang belum tahu, bahwa dalam kajian ilmu aldabt/diakritik, ternyata sebagian besar penyusunan diakrtitik mushaf merujuk kepada dua karya yang disusun pada abad ke-5 hijriyah oleh syaikhāni, yakni: 1) kitab almuḥkam karya Abū 'Amar al-Dānī sebagai pendamping kitab rasm (al-muqni' fi ma'rifah mașāhif al-amṣār, dan 2) kitab uṣūl al-ḍabt karya Abū Dāwūd Sulaimān bin Najāh yang juga sebagai pelengkap kitab (mukhtasar al-tabyïn li hijä' al-tanzīi). Kedua karya ini membahas tentang pemberian tanda baca tertentu yang bertujuan untuk membedakan bacaan antara penanda vokal yang disebut dengan (التشكيل الإعرابي) dan bacaan penanda konsonan yang disebut dengan (التشكيل الإعجامي) yang satu dengan lainnya terkadang memiliki kesamaan bentuk dan bacaan. Tidak itu saja, ilmu al-ḍabt pada kedua karya tersebut merangkum sejumlah jenis penanda rasm dalam enam kaidah dasar (الرسم فى ست قواعد استقل) yakni kaidah al-ḥażf, al-ziyādah, al-ibdāl, alwaṣl wa al-fașl, al-hamazāt, dzū al-qirā'atāni.

Stressing penelitian ini, lebih fokus kepada kajian karya Abū Dawud pada kitab usul al-ḍabt, dengan alasan mazhab Abū Dāwūd dalam ilmu rasm mushaf lebih diunggulkan ketimbang madzhab gurunya al-Dānī, khususnya dalam penulisan dan penyalinan mushaf-mushaf Madinah. Hal ini dibuktikan dengan keterangan (ta'rif alMuṣhaf) bahwa penyalinan Mushaf Madinah yang diterbitkan oleh Mujamma' Malik al-Fahad li al-Tibā'ah Muṣhaf al-Syarīf yang lebih dominan men-tarjīh pendapat Abū Dawud. Oleh karena itu diaktrikal al-Quran menurut preferensi Abū Dawud penting

\footnotetext{
${ }^{8}$ Hisyami bin Yazid, Risālah Fì 'Ilmi Dabt Al-Qur'ān Li Hal Al-Musykilah Al-Hadisah Mā Fì Rasm Al-Mushafi Al- 'UȘmānī. (Banda Aceh: Ar-Rijal Publisher, 2012), h. 171.

9 Muhammad Aqib Mayabi al-Junki al-Syinqiti, Nazam Rasyf Al-Lama 'ala Kasyf Al-'Ama (Omman: Dar al-Iylaf al-Dauliyah, 2012), h.12.
}

\section{'A Jami Jurnal Bahasa dan Sastra Arab}


untuk dikaji, sehingga dapat diketahui kecenderungan pilihan beliau, sebagai sumber rujukan dalam ilmu al-dabt al-muṣhaf.

Preferensi atau (preference - inggris) dimaksud mengandung arti "lebih suka, prioritas, kecenderungan, kesukaan dan pilihan". ${ }^{10}$ Dalam bahasa Arab term preferensi

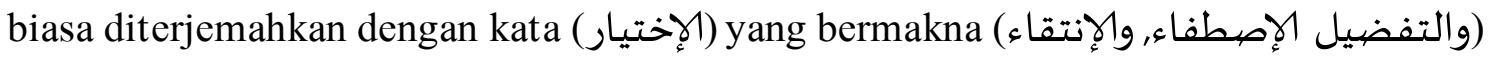
كأن أأخر الإرادة مع ملاحظة ما للطرف) sedangkan secara istilah didefenisikan dengan (المختار ينظر إلى الطرفين ويميل إلى أحدهما mendahulukan mengutamakan pendapat sendiri dari pendapat yang lain. Menurut Porteus Preferensi merupakan bagian dari komponen pembuat keputusan secara individu, sehingga setiap individu memiliki Preferensi dalam menentukan pilihan sesuai kecenderungannya". 12

Penelitian tentang al-dabt saat ini sangat penting untuk dikaji, mengingat cetakan al-Quran di berbagai negara seperti seperti wilayah masyriq, ${ }^{13}$ magribi ${ }^{14}$ (Moroko), dan (Indo-pak Quranic sript) rasm India Pakistan yang banyak bertebaran di Indonesia, Malaysia dan Brunai Darussalam yang juga memeliki bentuk diakritik yang berbeda-beda. Hal ini terlihat pada hasil penelitian terhahulu yang dilakukan oleh, Rudi Wahyudi Rudi, ${ }^{15}$ Abd Rahmah, ${ }^{16}$ Nur Hajar Rohmah ${ }^{17}$ dan Zaenal Arifin Madzkur. ${ }^{18}$ Oleh kerena itu titik pembeda penelitian ini dengan penelitian sebelumnya lebih kepada raj'ul al-Mașādir (mengungkapkan isi kitab yang menjadi rujukan utama dalam ilmu d̦abt, yang salah satunya ditorehkan oleh syaikh Abu Dawud dalam kitab uṣul aldabt. Sedangkan contoh-contoh penerapan diakritik al-Qur'an diambil dari mushaf Madinah berbasis aplikasi (مصحف المدينة المنورة للنشر الحاسوبي) yang diproduksi dan 1978

${ }^{10}$ Pusat Bahasa, Kamus Bahasa Indonesia (Jakarta: Departemen Pendidikan Nasional, 2008), h.

${ }^{11}$ Abū Al-Baqā' Al-Kafwìi, Al-Kulliyat (Beirut: Mu'assasah al-Risalah, n.d.), h. 62.

12 John Douglas Porteus, Environment and Behavior Planning and Everyday Urban Life. (Boston: Addison-Wesley, 1997), h. 10.

${ }^{13}$ Wikipedia, “Arab Masyriq," meliputi : Arabi Saudi, Mesir, Sudan, Yaman Omman, Kuwait, Iraq, Uni Emirat, Syiryah, Jordaniah dan Libanon Britannica.Com/Place/Mashriq, last modified 2019, https://id.wikipedia.org/wiki/Arab_Masyriq.

${ }^{14}$ Wikipedia, “Arab Magrib,” meliputi: lima negara di Afrika, Maroko, al-Jazair, Tunisia, Libya Mauritania, sampai ke wilayah Andalusia, Qordoba (Spanyol), Sisilia dan Malta, The Columbia Encyclopedia, last modified 2001, http://www.north-africa.com/. Arabia" (2018).

15 Rudi Wahyudi, “Perbandingan Mushaf Al-Qur'an Standar Utsmani Indonesia Dan Saudi

16 Abd Rahman, "Perbandingan Rasm Usmani Antara Mushaf Standar Indonesia Dan Mushaf Pakistan Perspektif Al-Dānī ‘Analisis Kaidah Hażf Al-Harf Dalam Rasm Usmani,’” 2018.

${ }^{17}$ Hajar Nur Rohmah, Kajian Rasm Mushaf (Perbandingan Antara Mushaf Standar Indonesia Dan Mushaf Maroko) (IAIN SALATIGA, 2020).

${ }^{18}$ Zaenal Arifin Madzkur, "Diskursus Ulumul-Qur'an Tentang Ilmu Dabth Dan Rasm Usmani; Kritik Atas Artikel Karakteristik Diakritik Mushaf Magribi, Arab Saudi Dan Indonesia," SUHUF Jurnal Pengkajian Al-Qur'an dan Budaya 8, no. 2 (2015): h. 261-282.

'A Jami Jurnal Bahasa dan Sastra Arab

ISSN: 2252-9926 (Print), ISSN: 2657-2206 (Online) 
disebarluaskan oleh Mujamma' Malik al-Fahd li Tiba'ah al-Mushaf al-Syarif. ${ }^{19}$ Oleh karena itu tujuan penelitian ini adalah untuk mendeskripsikan preferensi tokoh Abū Dāwūd agar terurai dengan tepat dan sejelas mungkin kecenderungan pilihan beliau tentang tanda diakritik al-Qur'an bersamaan dengan contoh serta argumentasinya.

Metode penelitian yang digunakan adalah penelitian kualitatif deskriptif, dengan cara menggambarkan, mengelompokkan secara objektif data yang dikaji sekaligus menganalisis dan mendeskripsikannya. Dilihat dari objeknya penelitian ini adalah penelitian kepustakaan, (library research), sehingga teknik pengumpulan data dilakukan dengan cara, membaca, mengklasifikasi, mengurai dan menyimpulkan sumber primer dari kitab ușūl al-ḍabt wa kaifiyatuhū ala jihhah al-Ikhtișâr ${ }^{20}$ karya Abu Dawud dengan pendekatan content analysis (analisis isi) guna "mendapatkan gambaran isi apa adanya secara objektif". 21

\section{B. Pembahasan dan Hasil Penelitian}

\section{Diakritik al-Qur'an}

Dalam ilmu rasm al-mushaf, diakritik merupakan cabang ilmu al-Qur'an yang menitik beratkan pada ilmu tanda pada huruf (علم الضبط). Kata (الضبط) secara bahasa berarti “mengatur, menawan, menjaga, mengurung dan memberi syakal' Orang Arab menggunakan kata ini dengan ungkapan (لزوم الشيئ أو حبسـ) "mengetatkan

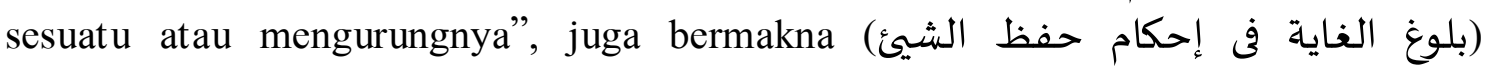
"tercapaiannya tujuan dalam menjaga sesuatu secara tepat/akurat", oleh karena itu bila seseorang disebut (الرجل الضابط) bermakna orang yang "kuat dan terjaga hafalannya". Dari pengertian di atas, menunjukan makna kata ḍabt ditujukan untuk menjaga dan memastikan huruf-huruf tertentu tepat cara penyebutannya melalui identitas syakal-nya. Adapun secara istilah sebagaimana yang diungkapkan oleh alDabba' dan al-Kharrāz adalah :

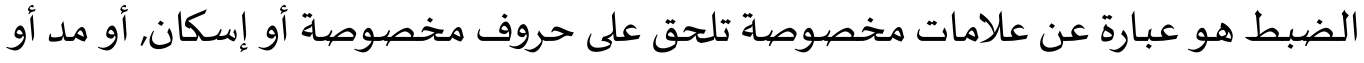

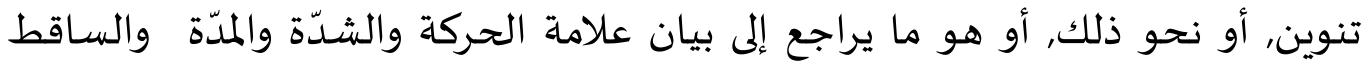

$$
\begin{aligned}
& \text { والزائد. }
\end{aligned}
$$

${ }^{19}$ Mujamma' Malik al-Fahd li Tiba'ah al-Mushaf al-Syarif., "Mushaf Al-Madinah AlMunawarah Li Al-Nasyr Al-Hasubi," Al-Madinah Al-Munawwarah, last modified 2015, https://bookslibrary.online/free-124029141-download.

${ }^{20}$ Abu Dawud Sulaiman bin Najah, Ușūl Al-Ḍabt Wa Kaifiayatuhū Ala Jihhah Al-Ikhatiṣār (Madinah Munawwarah: Mujamma' Malik al-Fahd li Tibā'ah Muṣhaf al-Syarif, 2006) h. 1-344.

${ }^{21}$ Jumal Ahmad, "Desain Penelitian Analisis Isi (Content Analysis)," ResearchGate, no. June (2018): 1-20, https://www.researchgate.net/publication/325965331.

\section{'A Jami Jurnal Bahasa dan Sastra Arab}


"al-Dabt adalah istilah untuk tanda-tanda khusus, yang disematkan pada hurufhuruf tertentu, baik berupa sukūn, mad, tanwin dan lain sebagainya, ${ }^{22}$ atau istilah ditunjukkan kepada sebuah tanda harakat, berupa sukūn, tasydid, mad, huruf yang dieliminir dan ditambah". ${ }^{23}$

Term al-ḍabt bersinonim dengan kata syakal, harakat dan i’jam. Syakal dan harakat adalah pemberian tanda vokal pada huruf konsonan agar memiliki identitas bunyi (a-i-u-), juga tanda tidak bervokal pada huruf konsonan yang dibaca dengan nafas tertahan atau ganda, sehingga muncullah istilah fathah, kasrah, dammah, sukūn dan tasydid/syiddah. Adapun istilah i'jam adalah pemberian tanda untuk membedakan bunyi huruf yang sama bentuknya dalam bentuk titik (naqt) - (النقط الدال على ذات (الحروف وتمييز الحروف المتماثلة فى رسم من بعضها بوضع نقط يمنع العجمة واللبس (البس ), oleh

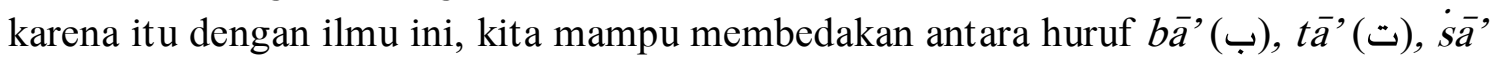
(ث) dan nün(ن), yang awalnya memang tidak memiliki titik.

Jika menilik sejarah embrio ilmu al-dabt pada hakekatnya telah dirintis oleh empat ulama, yakni Abū Aswad al-Du'ā̄i, kemudian dilanjutkan oleh Ỵahyā bin Ya'mar dan Naṣr bin 'Āṣim, disempurnakan oleh Khalil bin Ạ̣mad al-Farāhidì, yang bentuknya dulu masih sangat sederhana dan memiliki sistem pewarnaan, (hitam, merah, hijau dan kuning). ${ }^{24}$ Sedangkan menurut al-Zahrānī sebenarnya munculnya ilmu diakritik al-Qur'an diprakarsai oleh 6 ulama, sebagai berikut: 1) Abū al-Aswad alDu'ali (w 69 H), 2) Nāṣir bin 'Āṣim al-Laisīi (w. 90 H), 3) Yaḥyā bin Ya'mar al'Udwānī (w. 129 H), 4) Abdullāh bin Abì Ishạà al-Haḍramī (w. 127 H), 5) Abdurrahmān bin Hurmūz (w. 119 H), dan 6) Khalil bin Aḥmad al-Farāhidi (w. 170 H), dari keenam ulama tersebut Abū al-Aswad pada masa Daulah Umawiyah (abad ke-7 M) disebut-sebut sebagai pencetus pertama ilmu al-dabt beserta rumus-rumus pembeda (diacritical marks) berupa titik-titik yang dibubuhi dengan tinta berwarna merah yang membedakannya dengan batang huruf yang umumnya berwarna hitam. ${ }^{25}$

Adapun Khalìl bin Ahmad al-Farāhidi memformulasikan tanda diakritik dengan pola al-qalb/taqlibi "proses pembalikan", seperti: Alif (।) dikecilkan sebagai tanda a/fathah dengan bentuk miring diletakkan di atas huruf, dan tanda $\mathrm{i} /$ kasrah

${ }^{22}$ Muhammad 'Ali al-Dabbā', Sāmir Al-Ṭālibīn Fì Rasm Wa Dabt Al-Kitāb Al-Mubīn, ed. Abd al-Hamid Ahmad Al-Hanafí, 1st ed. (Mesir, n.d.), h. 154.

${ }^{23}$ Muhammad bin 'Abdullah Al-Tunisī, Al-Ṭirāz Fi Syarh Dabt Al-Kharrāz, Tahqiq: Muhammad Syirsyăl (Madinah Munawwarah: Mujamma' Malik al-Fahd li Tibā'ah Muṣhaf al-Syarifi, 2000), h. 27.

${ }^{24}$ Abd Al-Ḥayy Ḥusain Al-Farmāwī, Rasm Al-Mus̄haf Wa Naqtuhu (Makkah: al-Maktabah alMakkiyah, 2004).

${ }^{25}$ Sālim bin 'Abdullāh bin Muhammad al-Zahrānī, Dabt Al-Qur'an Al-Karim: Nasy'atuhu, Wa Ta Tawwuruhu, Wa "Ināyah Al-'Ulama” Bihi (Makkah al-Mukarramah: Jami'ah Umm al-Qurā, n.d.), h. 58.

\section{'A Jami Jurnal Bahasa dan Sastra Arab}

ISSN: 2252-9926 (Print), ISSN: 2657-2206 (Online) 
diletakkan di bahwa huruf, (و) dikecilkan sebagai tanda u/ḍmmah. Kepiawaian Khalil dalam diakritik al-Qur'an yang ditandai dengan kreasi beliau dalam menghadirkan syakal-syakal yang dimodif dari potongan-potongan ortografi Arab, seperti tanda sukūn (户)diambil dari kepala (ح), tanda tasydid (户) diambil dari potongan huruf (w), hamzah ( $)$ diambil dari potongan huruf $(\varepsilon){ }^{26}$

Dilihat dari segi hukumnya, para ulama berbeda pendapat tentang ilmu ini, ada yang melarang, adapula yang membolehkannya. Kelompok yang melarang diakritik al-Qur'an dilandasi dengan alasan, bahwa tulisan al-Qur'an tidak boleh dimasuki oleh tanda-tanda apapun yang tidak pernah dilakukan oleh nabi, dicontohkan oleh para sahabat sesudahnya secara pasti, sehingga keberadaanya harus tetap terjaga seperti awalnya, tanpa ada tambahan, perubahan dan masuknya tanda-tanda yang asing, aneh yang bukan merupakan batang tubuh tulisan al-Qur'an. Dengan alasan itu para ulama salaf banyak yang melarangnya. ${ }^{27}$ Sedangkan bagi kelompok yang membolehkannya, didasari oleh alasan maslahah ḍaruriyah yang mendesak dan dibutuhkan pada saat itu, agar tidak terjadi laḥn al-qirä'ah, yang memunculkan perdebatan pendapat, dan klaim kebenaran sepihak, serta menuduh bacaan lain menyimpang dari bacaannya. Hal ini cukup beralasan karena antara lidah dan dialek orang Arab dengan orang $A$ 'jam memiliki perbedaan yang cukup signifikan, yang jika dibiarkan akan berujung pada kerusakan bahasa, dan kesalahan makna. Hal ini pernah terjadi pada kasus kesalahan bacaan pada surah al-Taubah ayat 3 .

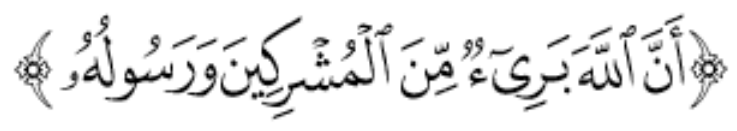

Pada saat itu Abū Aswad al-Du'ali mendengar ada yang membaca dengan kasrah pada kata (وَرَسُوْلِيها). Tentu hal ini berefek pada kesalahan makna menjadi: "Sesungguhnya Allah berlepas diri dari orang-orang musyrik dan rasulnya." padahal yang benar dibaca dammah, sehingga bermakna "Sesungguhnya Allah dan rasulnya berlepas diri dari orang-orang musyrik.". Dari contoh kasus tersebut, dapat dibayangkan apa yang akan terjadi bila al-Quran yang kita baca, tanpa dibubuhi syakal/ harakat dan titik?. Oleh karena itu, perbedaan pendapat dua kelompok di atas menurut penulis sangat logis, karena kelompok yang melarang, bertujuan agar alQur'an tetap orisinil, tanpa perubahan, sedangkan kelompok yang membolehkan tidak lain karena al-Quran tidak hanya diperuntukkan kepada orang Arab saja, sehingga untuk menghindari kekeliruan dan kesalahan bacaan ilmu al-dabt wa al-naqt sangat

\footnotetext{
${ }^{26}$ Damhuri Dj. Noor dan Muhtar Miolo, "Kontribusi Al-Khalil Bin Ahmad Al-Farahidi Dalam Ilmu-Ilmu Bahasa Arab,” Al-Lisan: Jurnal Bahasa 5, no. 2 (2019): h. 148-160.

${ }^{27}$ Ussmān bin Sa’ìd Al-Dānī, Al-Muḥkam Fì Naqt Al-Maṣāhif, ed. Izzah Hasan (Damasqus, Suriah: Dār al-Fikr, 1986), h.11.
}

\section{'A Jami Jurnal Bahasa dan Sastra Arab}


dibutuhkan. Hal ini dibuktikan pula dengan hadirnya beberapa kitab rujukan ilmu alrasm wa dabt yang ada sejak Abad ke V hijriyah, yang menjadi tonggak lahirnya ilmu rasm dan

Jika melihat pada karakterisik diakritik al-Qur'an, dari awalnya terus mengalami perubahan bentuk, sampai menjadi apa yang kita lihat sekarang pada mushaf. Karena diakrtitik al-Qur'an bersifat ijtihadi, maka kemunculannya dipengaruhi oleh kultur wilayah budayanya, yang dikenal dengan ḍabt masyriq dan ḍabt magrib. Perbedaan kedua istilah ini nampak bentuk sukūn, untuk wilayah masyriq tanda sukūn diambil dari kepala huruf $h \bar{a}$ ' $(\tau)$, sedangkan untuk wilayah magrib berbentuk bulatan menyerupai nol/sifr (0). Dari sini pula kita dapat mengetahui bahwa ilmu diakritik alQuran memiliki akar sejarah yang kuat dan berkesinambungan yang ditandai dengan adanya sejumlah referensi yang ditorehkan oleh para ulama rasm, dan salah satunya terdapat pada kitab uṣūl al-ḍabt karya Abū Dāwūd.

\section{Macam-macam Diakritik al-Quran}

Merujuk pada sejumlah referensi ilmu al-dabt, disebutkan bahwa ada kurang lebih 10 tanda yang digunakan dalam memberi tanda diakritik al-Quran, yakni 1) Tanwin, 2) Fathah, 3) Kasrah, 4) Dammah, 5) Sukun, 6) Tasydid, 7) Tanda Panjang/mad, 8) Tanda huruf yang dibuang/hażf, 9) Tanda Huruf yang ditambah/ziyādah dan 10) Tanda waqaf, wasl dan tanda yang terkait dengan qira'at. Kesepuluh jenis tanda tersebut menghiasi mushaf-mushaf cetakan timur tengah, seperti Madinah, Libya, Mesir, Iran dan Turki, namun jika merujuk pada buku pedoman pentashihan mushaf al-Quran Indonesia ditemukan sejumlah tanda diakritik yang sedikit berbeda dengan kesepuluh tanda di atas, meskipun secara umum ada yang sama. Tanda-tanda Diakritik tersebut adalah 1) Fathah Qä'imah, 2) Kasrah Qä'imah, 3) Dammah Maqlübah, 4) Sukūn, 5) Syiddah/tasydid, 6) Tanda garis bergelombang untuk mad jā'iz munfasil, 7) Tanda garis lengkung tebal, untuk bacaan mad wājib muttașil, mad lāzim dan mad farq, 8) Sïn kecil terletak di atas huruf șād, 9) Sifrun Mustatīil berbentuk bulat lonjong, 10) Șifrun Muștadir berbentuk bulatan bulat, serta 11) tanda yang terkait dengan qira'at tertentu, seperti saktah, isymām, tashīl, dan imālah. ${ }^{28}$ Untuk lebih memperjelas tanda diakritik al-Qur'an dapat dilihat pada tabel berikut:

28 Lajnah Pentashihan Mushaf Al-Quran, Pedoman Penstahihan Mushaf Al-Quran, 1st ed. (Jakarta, 2015), 63.

\section{'A Jami Jurnal Bahasa dan Sastra Arab}




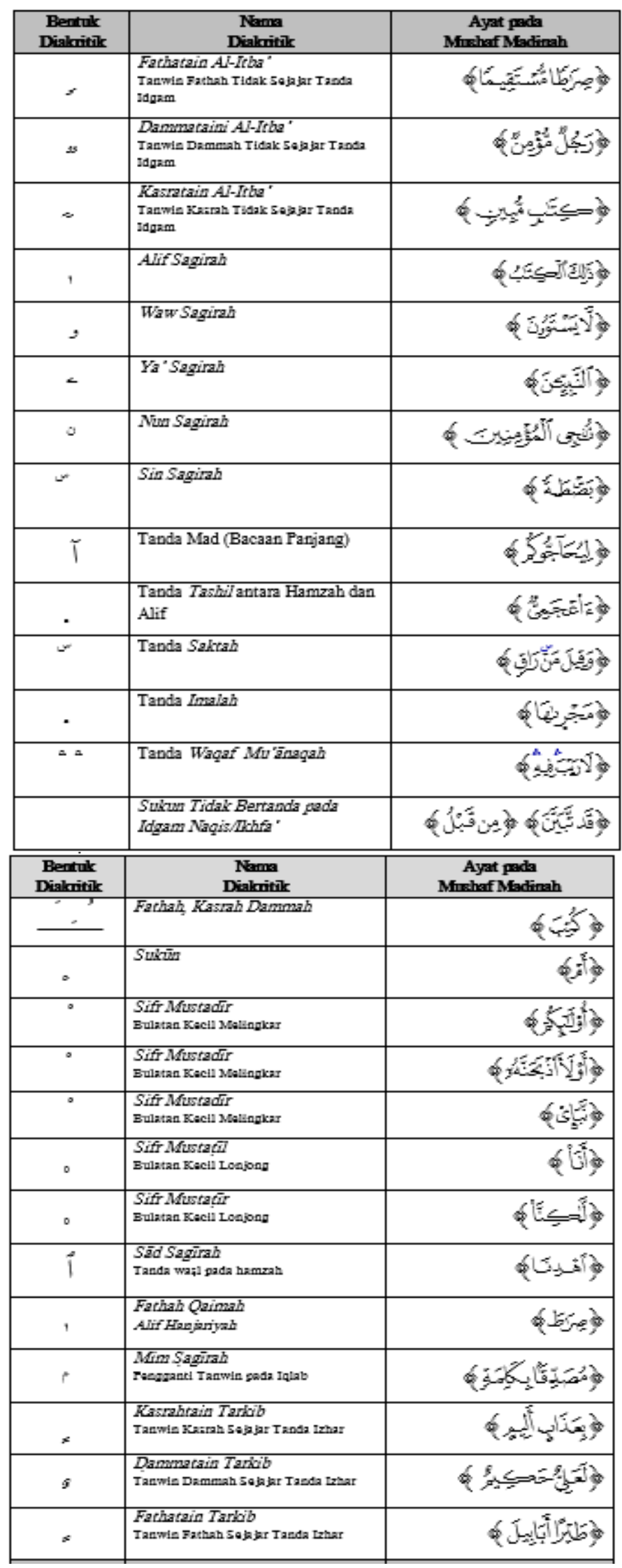

\section{'A Jami Jurnal Bahasa dan Sastra Arab}




\section{Sekilas tentang Kitab Ușūl al-Ḍabt}

Pada bagian ini penulis akan memaparkan sekilas tentang karya monumental beliau yang masih ditemukan bentuk dalam bentuk PDF, yakni Ușül al-Ḍabt wa Kaifiyatuhu ala wajh al-Iktisär, kitab ini lebih menitik beratkan pada diaktritik alQur'an yang juga sebagai pelengkap al-Tanzīl yang mengurai secara tahlili teknis penyalinan dan penulisan al-Quran dari surah al-Fatihah s/d surah al-Nas. Dari aspek penamaan kitab, terkadang Abū Dāwūd sesekali menyebutnya dengan nama kitab alNaqt, kadang pula dengan nama kitāb al-Ḍabt dan Ușūl al-Ḍabt, sedangkan dalam penjelasan kitab Maurid al-Zam'ān dinamai dengan (الذيل) "ekor” ( الأن المؤلف جعله ذيلا لكتابه مختصر التبيين لهجاء التنزيل dengan uṣull al-ḍabt wa kaifiyatuhu ala jihhah al-Ikhtisăr, tidak lain karena demikian yang ditulis oleh Abū Dawud pada muqaddimah kitabnya. ${ }^{29}$

Menurut beberapa literatur, bahwa ketika Abū Dawud telah menyusun sebuah kitab besar yang diberi nama al-tabyīn li hijā' al-Tanzîl, yang itu merujuk kepada kitab mukhtasar al-Tabyin yang bentuknya cukup besar dan tebal, sedangkan isinya merangkum macam-macam ilmu al-Qur'an dan Tafsir, maka pada saat itu munculah permintaan dari berbagai wilayah yang sebagian besar adalah murid-muridnya, agar materi tentang cara penulisan dan ejaan huruf-huruf al-Quran tersebut diringkas tanpa ada yang dikecualikan. Maka dijadikanlah kitab al-tabyin li hijā' al-Tanzīl sebagai pangkal dan asal muasal ilmu al-ḍabt dengan versi qirā'at imam al-Nāfi' al-Madanī dan orang-orang yang sepakat dengan bacaan itu. Hal dapat dimaklumni karena sebagian besar mushaf di Andulusia pada saat itu, diberi tanda diakritik berdasarkan versi bacaannya. Abū Dawud berkata: "Buku ini di dalamnya menyebutkan tentang pondasi ilmu dabt al-Qur'an (tanda diakritik) berdasarkan bacaan qira'at imam alNāfi'bin Abi Nu'aim bersama dengan semua bacaan yang disepakati oleh kebanyakan imam Qiraat lain. Jadi Aku telah menyendirikan satu kitab khusus ilmu al-dabt yang didalamnya menghimpun al-qirāah al-Sab'ah dari semua tariq-tariq-nya, dengan maksud untuk meringkas. (الإختصهار)" ${ }^{30}$ Dari keterangan di atas menunjukkan bahwa kitab usul al-Dabt dijadikan oleh Abū Dawud sebagai pelengkap dan pelanjut karya sebelumnya mukhtasar al-Tabyin li Hija' al-Tanzil.

Kitab ini dalam bentuk PDF, dicetak dan disebarluaskan oleh Mujamma' alMalik Fahd Arab Saudi melalui kementerian Agama, al-Waqf, al-Dakwah dan al-Irsyad

${ }^{29}$ Abū Dāwūd Sulaiman bin Najāh, Kitāb Usūul Al-Dabt Wa Kaifiyatuhu 'ala Jihhah AlIkhtisār, ed. Ahmad bin Ahmad bin Mu'ammar Syirsyāl (al-Mamlakah al-'Arabiyah al-Sa'udiyah: Mujamma’ Malik al-Fahd li Tibā'ah Muṣhaf al-Syarif, 2010), 13.

${ }^{30}$ Abū Dāwūd Sulaiman bin Najāh, Kitāb Ușūl Al-Ḍabt Wa Kaifiyatuhu 'ala Jihhah AlIkhtisār, ed. Ahmad bin Ahmad bin Mu'ammar Syirsyāl (al-Mamlakah al-'Arabiyah al-Sa'udiyah: Mujamma' Malik al-Fahd li Tibā'ah Muṣhaf al-Syarif, 2010), 13.

\section{'A Jami Jurnal Bahasa dan Sastra Arab}


al-Madinah Munawwarah, atas kerja keras muhaqqiq Ahmad bin Ahmad Mu'ammar Syisyāl, dengan jumlah halaman sebanyak 344, dengan ukuran 16 x $25 \mathrm{~cm}^{31}$

Dari aspek isinya, kitab ini sangat penting dirujuk dalam kaitannya dengan ilmu diakritik al-Qur'an, mengingat pada masa itu kitab khusus tentang ilmu diakritik/ḍabt dalam bentuk tulisan tangan sangatlah langka. Oleh karena itu kitab tersebut disebutsebut sebagai kitab pertama selain al-muhkam karya al-Dāni yang secara rinci menjelaskan tentang tanda baca, syakal dan titik al-Qur'an, bahkan pada generasi sesudahnya kitab ini sering pijakan/sandaran dalam ilmu ḍabt, seperti yang dilakukan oleh al-Muqri' al-Hasan al-Manbahì al-Syabānì:

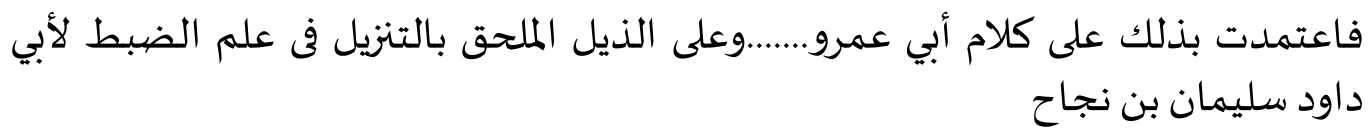

Abū Dāwūd dalam menyusun kitabnya, meski memiliki otoritas sendiri, tidak sedikit pendapat dan pandangannya men-tarjīh pendapat gurunya (al-Dāni), bahkan menurut Syirsyāl kitab tersebut berhasil memadukan pola diakritik yang ditorehkan oleh Abū Aswad al-Du'āTi tentang titik/naqt dan pola diakritik Khalil Ahmad alFarahidi tentang syakall harakat.

Dari aspek metodologi penyusunan kitabnya, Abū Dawud sebelum menjelaskan sesuatu, beliau berbicara tentang tema-tema tanda harakät dan tanwin, kemudian diikuti dengan penjelasan tentang ikhtilạs dan al-Isymām, kemudian sesekali menukil pendapat al-Dānì, dan menginfomasikan jika berbeda pendapat dengan gurunya. Selanjutnya beliau membahas tentang macam-macam tanda sukūn pada bab tasydid dan menjelaskan tentang teknisnya. Abū Dawud juga cenderung memilih pendapat ahli al-Madinah yang sesuai dengan pendapat Khalil Ahmad al-Farāhidi tentang penggunaan huruf syin sebagai tanda tasydid, bahkan beliau sering menolak pandangan yang menurutnya janggal dan asing. Selanjutnya beliau menyentil pula tentang hukum menyambung alif al-wașl pada bacaan warsy, dan tanda alif wașl pada permulaan beserta bentuk naqt-nya, membahas tentang hukum nun sukūn, iẓhär, idgām dan pola tandanya bersamaan dengan menjelaskan tentang sejumlah ittifäq dan ikhtiläf para ulama. Di bagian akhir beliau melengkapi kitabnya dengan bahasan mengenai tandatanda yang berlaku pada hukum mad, melembutkan huruf hamzah, hamzah mufrad, dua hamzah pada satu dan dua kata, tanda alif làm muzfarah, serta bentuk tanda diakritik tambahan pada huruf alif, yā', dan wāw, dari penjelasan di atas, dapat diketahui bahwa isi kitab uṣūl al-ḍabt terdiri dari 15 pokok bahasan.

\footnotetext{
${ }^{31}$ Zainul Arifin Madzkur, “Survei Bibligrafis Kajian Penulisan Al-Qur'an, Studi Literatur Rasm Usmani Dari Masa Klasik Sampai Modern.”, h. 161.
}

\section{'A Jami Jurnal Bahasa dan Sastra Arab}




\section{Diakrtik al-Qur'an menurut Preferensi Abū Dāwūd}

\section{a. Tanda diakritik pada Idgām al-Nāqis}

Idgam Naqis adalah apabila huruf pertama hanya zatnya saja yang masuk pada huruf kedua, sedangkan sifatnya tidak. Sifat huruf pertama tetap ada dan mengakibatkan pengucapan tasydid tidak sempurna karena terselubung dengan sifat huruf pertama diucapakan secara bersamaan. Hal ini berbeda dengan idgam kāmil, yakni apabila huruf pertama masuk pada huruf yang kedua, baik makhraj maupun sifat hurufnya, sehingga menghasilkan pengucapan dengan tasydid yang sempurna.

Dalam hal ini terdapat dua pandangan: 1) Huruf (b) diberi tanda diakritik sukun, sedangkan huruf (ت) sesudahnya diberi tanda diakritik tasydid, 2) Huruf (b) tanpa dibubuhi tanda diakritik sukūn, dan huruf (ت) juga tanpa dibubuhi tanda diakritik tasydid.

Terhadap kedua pandangan di atas, menurut Abū Dawūd bahwa keduakedua-nya bagus (كلا الوجهين عندي حسن, والؤل أختار), namun beliau memiliki preferensi pada pandangan pertama, bahwa, apabila terjadi pertemuan antara huruf (b) dengan (ت) dalam satu kata, maka zat huruf (b) tetap nampak dibaca, seakan terdapat bacaan tanda tasydid pada kata itu, sehingga huruf (b) tanpa dibubuhi harakat sukun, contoh pada kata (بَسَطتَ - وأَحَطتُ - مَا فَرَّطتُمْ (مَ). Preferensi beliau dibangun atas dasar, bahwa huruf (ط) memiliki sifat al-Itbaq, ${ }^{33}$ sehingga dengan tanpa memberi tanda sukun mengarahkan kepada pembaca bahwa sifat hurufnya harus muncul dan tidak terbalik dan didahului oleh suara huruf (ت). Alasan lain, karena yang mengikuti pendapat gurunya al-Dānì, sehingga beliaupun memilih pendapat tersebut. Pada prakteknya, antara mushaf ahl al-masyriq dan ahl almagrib-pun berbeda, dimana ahl al-magrib memilih pendapat pertama, sedangkan ahl al-masyriq memilih pendapat yang kedua.

\section{b. Tanda diakritik pada Huruf Mad al-Mahzüf}

Pada kasus tanda diakritik mad al-mahzüf, baik terletak setelah hamzah dan sukūn atau terletak sebelum huruf lainnya. Artinya bahwa jika posisi hamzah didahului oleh mad, $^{34}$ maka kata tersebut tidak diberi tanda mad, kecuali menurut bacaan imam Warsy. ${ }^{35}$ Hal ini dapat dilihat pada beberapa contoh kata berikut:

\footnotetext{
${ }^{32}$ Abū Dāwūd Sulaiman bin Najāh, Kitāb Ușūl Al-Ḍabt Wa Kaifiyatuhu 'ala Jihhah Al-Ikhtisār,
} 105.

33 It $b \bar{a} q$ secara bahasa berarti lengket. Menurut istilah, It $b \bar{a} q$ sebagai sifat huruf adalah cara pengucapan khuruf dengan mempertemukan permukaan lidah dengan langit-langit. huruf It pada empat khuruf, (ص-ض-b) Abdul Mujib Ismail dan Mariah Ulfah Nawawi, Pedoman Ilmu Tajwid, Surabaya: Karya Aditama, 1995), 57.

${ }^{34}$ Mad (bahasa Arab: المد, "al madd") secara harfiah bermakna melanjutkan atau melebihkan, secara istilah mad dapat diartikan sebagai tanda bunyi panjang dalam bahasa Arab (bunyi pendek

\section{"A Jami Jurnal Bahasa dan Sastra Arab}




\begin{tabular}{|c|c|c|}
\hline No & Surah & Redaksi \\
\hline 1 & Al-Rum: 13 & 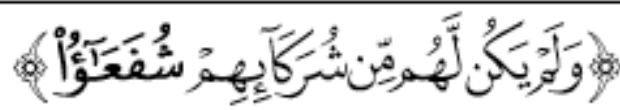 \\
\hline 2 & Al-Kahfi; 16 & \\
\hline 3 & Ali Imran : 7 & 8 \\
\hline 4 & Al-Saffat : 1 & 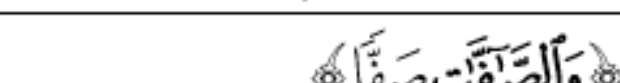 \\
\hline 5 & Al-An'am : 81 & 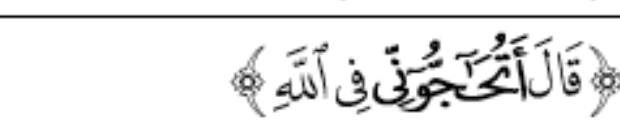 \\
\hline
\end{tabular}

Dalam hal ini terdapat dua pendapat, 1) Menuliskan huruf alif, waw, ya mahzüf (yang dibuang), dengan tanda merah. Tanda merah tersebut dirancang agar tidak bercampur dengan tanda lain, dan ini terdapat pada mushaf-mushaf kuno. 2) Tidak menuliskan huruf apapun pada kata itu, namun memberikan tanda simbol (المطة), bahwa pada kata tersebut telah terjadi haż alif, waw dan ya. Terhadap kedua pendapat di atas, Abū Dawud cenderung memilih pendapat pertama, yakni apabila kata tersebut memilih bacaan mad/panjang, dan sesudahnya terdapatt huruf

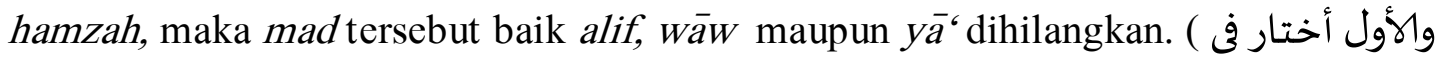
هengan alasan bahwa asal sebuah mad (tanda panjang) sebenarnya harus dibubuhi oleh tanda yang menunjukkan adanya bacaan panjang pada kata itu, namun jika tidak ditulis, maka tetap harus menjaga keaslian mad tersebut. Setelah berjalannya waktu keberadaan penulisan seperti ini tetap dibubuhi tanda sebagai simbol fathah qāimah/alif hanjariyah șagìrah, wāw șagïrah dan yā' sagïrah, dan pola inilah yang diikuti oleh mushaf cetakan Madinah yang kita baca sekarang.

Pada contoh lain, ditemukan, bahwa jika sebuah kata yang mengandung bacaan mad, tidak memiliki tanda sukun atau hamzah, maka pada keadaan seperti itu, para ulama berbeda pendapat dan memunculkan pada dua pilihan, 1) Menyertakan huruf mad al-mah̆züf tanpa meletakkan tanda mad far'i tertentu

menjadi bunyi panjang). Dari segi istilah ulama tajwid dan ahli bacaan, mad bermakna memanjangkan suara dengan lanjutan menurut kedudukan salah satu dari huruf mad. Terdapat dua bagian mad, yaitu mad ași dan mad farí. Terdapat tiga huruf mad yaitu alif, waw, dan yā'dan huruf tersebut haruslah berbaris mati atau saktah. Panjang pendeknya bacaan mad diukur dengan menggunakan harakat.

${ }^{35}$ Ahmad Yusam Thobroni, "Ibnu Mujahid Dan Konstribusinya Dalam Qira'at Al-Qur'an,” AlFikra: Jurnal Ilmiah Keislaman 7, no. 1 (2017): 63-79.

${ }^{36}$ Al-Tunisī, Al-Ṭirāz Fị Syarḥ Dabt Al-Kharrāz, h. 122.

\section{'A Jami Jurnal Bahasa dan Sastra Arab}


padanya, ${ }^{37}$ 2) Tanpa melekatkan huruf mad mah̆żüf dan cukup menempatkan tanda mad far'ī pada tempatnya, perhatikan tabel berikut:

\begin{tabular}{|c|c|c|}
\hline No & Surah & Redaksi \\
\hline 1 & al-Insyiqāq : 15 & \\
\hline 2 & Hūd : 105 & \\
\hline 3 & Al-Kahfi : 24 & \\
\hline
\end{tabular}

Terhadap dua pendapat di atas, Abū Dawud cenderung memiliki preferensi pada pendapat pertama bahwa, pada kata tersebut harus diberi simbol wāw dan yā', mah̆züf. Hal ini untuk membedakan antara ukuran simbol mad al-mah̆żüf dengan tanda mad far'i.

\section{c. Tanda Diakritik pada Hamzah}

Penulisan hamzah merupakan huruf yang cukup rumit dalam ilmu rasm dan dabt, hal ini karena hamzah memiliki beberapa varian bentuk, baik terletak pada awal kata, tengah maupun akhir kata, disamping itu para ulama terdahulu banyak menaruh perhatian terhadap masalah penulisan hamzah ini, karena terkait dengan masalah qira'at, khususnya yang terkait dengan kondisi dua hamzah yang terdapat awal kata, bertemunya hamzah dan alif pada awal kata, bertemunya hamzah istifham bersama hamzah wasl, bertemunya dua alif di tangah dan akhir kata dan bertemunya dua hamzah pada dua kata yang berbeda.

\begin{tabular}{|c|c|c|}
\hline No & Surah & Redaksi \\
\hline 1 & Al-Baqarah : 6 & \\
\hline 2 & A1-Isra' : 61 & 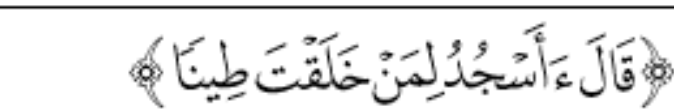 \\
\hline 3 & Al-Saffat : 53 & $6 َ$ \\
\hline 4 & Al-Nazi'at : 10 & \\
\hline 5 & Sad : 8 & $\varepsilon$ \\
\hline
\end{tabular}

${ }^{37}$ Huruf mad mah̆żü adalah simbol huruf kecil, berbentuk alif, wāw dan yā', sedangkan tanda mad adalah tanda bacaan panjang yang berlaku pada mad far'í yang bentuknya standar (أ -و - ي

\section{'A Jami Jurnal Bahasa dan Sastra Arab}


Contoh tabel di atas, nampak terjadi pertemuan antara hamzah istifham dan hamzah ași yang merupakan bagian dari akar kata, sedangkan pada mushaf kuno, tertulis dengan satu hamzah untuk menghindari terjadinya penggabungan dua bentuk hamzah sehingga cukup dengan satu bentuk saja. Terhadap kedua hamzah tersebut para ulama berbeda pendapat, mana hamzah yang harus dibuang ketika diterapkan dalam qira'at, sehingga memunculkan dua madzab, 1) Mazhab al-Kisā'i, yang berpendapat bahwa jika satu kata terdapat dua hamzah, maka yang dibuang adalah hamzah istifhäm, karena merupakan huruf tambahan dalam kata, sedangkan hamzah al-wașl atau al-qat' merupakan akar/asal kata, ini merupakan pendapat umum para penulis mushaf. 2) Mazhab al-Farrā', Śa'lab dan Kaisān, yang berpendapat bahwa hamzah hamzah al-wasl atau al-qat' yang harus dibuang, sedangkan hamzah istifham harus ditulis, karena posisinya sebagai mubtada' sedangkan mubtada' tidak bisa hilang tulisannya, dan keberadaanya membutuhkan khabar yang juga berdampak pada kesempurnaan makna, oleh karena itu baik tulisan maupun bentuknya wajib ada. Menanggapi kedua mazhab tersebut Abū Dawud membenarkan kedua pendapat tersebut, (والوجهان في ذلك صحيحان). Oleh karena itu para ulama muta'akhirin sering menggabūngkan kedua pendapat dari mażhab al-Farrā' dan mazhab al-Kisā'i tersebut dalam penulisan ayat, ada yang membuang/hazf huruf pertama dan menetapkan (isbat) huruf kedua, atau kebalikannya. ${ }^{38}$ Dengan demikian maka Abu Dawud lebih cenderung membenarkan kedua pendapat tersebut yang dilandasi oleh perbedaan qirā'àt.

\section{d. Tanda Diakritik pada dua huruf $Y \bar{a}$ '.}

Pada kasus ini, sering kita menemukan satu kata, yang didalamnya terdapat dua huruf yä, yang posisinya merupakan tempat hamzah, serta dua huruf yä' yang salah satunya merupakan tempat huruf hamzah, seperti contoh pada tabel berikut:

\begin{tabular}{|c|c|c|}
\hline No & Surah & Redaksi \\
\hline 1 & Al-Baqarah : 61 & \\
\hline 2 & Ali Imran : 75 & \\
\hline 3 & Ali Imran : 79 & \\
\hline
\end{tabular}

Terhadap contoh penulisan ayat di atas, para ulama rasm dan menaruhkan perhatian tentang teknis pemberian tanda diakritiknya, sehingga memunculkan dua pendapat. 1) Apabila terdapat dua yā' pada satu kata, maka $y \bar{a}^{-}$

${ }^{38}$ Al-Dabbā', Sāmir Al-Ṭālibīn Fì Rasm Wa Dabt Al-Kitāb Al-Mubīn, h. 203.

\section{'A Jami Jurnal Bahasa dan Sastra Arab}


yang menjadi asal sebuah kata yang dibuang/hazf, sehingga pada contoh di atas ya pada kata (النبيّ - الأميّ - ربنيّ) pertama dibuang sedang yā' kedua sebagai tanda jama“ harus tetap ada/isbāt, ini merupakan Pendapat al-Dani, 2) Apabila terdapat dua $y \bar{a}{ }^{-}$ pada satu kata, maka $y \bar{a}^{\star}$ yang menjadi tanda jama ' yang harus dibuang, karena $y \bar{a}^{\circ}$ tersebut hanyalah tambahan dan bukan akar kata, disamping itu membuang $y \bar{a}^{-}$ yang menjadi akar kata dapat merusak unsur keaslian kata tersebut. Terhadap hal ini, Abū Dawud berbeda pendapat dengan gurunya al-Dānì, dan cenderung memilih pendapat yang kedua yang menurutnya lebih baik, ia berkata : وأنا أخالف أبا عمرو فى ) 3ذا: هذا: وأقول إن المذهب الثاني أحسن عندي

\section{e. Tanda Diakritik pada Ziyādah huruf $Y_{\bar{a}}^{-}$.}

Ziyādah huruf yā' terdapat pada dua jenis, yakni 1) Ziyādah yā's setelah hamzah bersyakal kasrah yang belum didahului oleh alif,

\begin{tabular}{|c|c|c|}
\hline No & Surah & Redaksi \\
\hline 1 & Al-An'am : 34 & \\
\hline 2 & Ali Imran : 144 & \\
\hline 3 & Al-Zariyat : 47 & \\
\hline 4 & A1-Qalam : 6 & \\
\hline
\end{tabular}

Ziyādah huruf yā' merupakan pembahasan dalam bidang rasm dan oleh karena itu Abū Dawud memberikan informasi bahwa kasus-kasus diaktritik ziyadah yā' memiliki enam versi, dan itu telah disebutkan pada kitabnya al-tanzīl. Pada dua contoh di atas (نباى) dan (أفإين), Abū Dawud meletakkan tanda sifrah di atas hamzah, sedangkan harakatnya dibubuhi titik (nuqt) berwarna merah, dan pada huruf $y \bar{a}$ ' diberi tanda lingkaran (الدائرة) sebagai simbol bahwa huruf tersebut hanyalah ziyādahtambahan yang tidak dibaca. Adapun sebab preferensi beliau didasari oleh alasan bahwa yā ziyādah berfungsi memperkuat posisi hamzah, dan tanda diakritik yang melekat padanya dirasa pas, dan pendapat ini yang diikuti oleh para penyalin mushaf sehingga menjadi seperti sekarang ini.

Terkait dengan tanda diakritik pada kata (بأييد) dan (بأييكم) yang memiliki dua $y \bar{a}$, , Abū Dawud meletakkan tanda sukun pada yā', pertama, sebagai pembeda

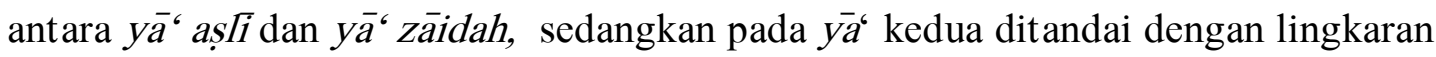
sebagai penanda bahwa huruf tersebut merupakan ziyādah. Adapun untuk

\footnotetext{
${ }^{39}$ Syirsyāl, Mukhtasar Al-Tabyin Li Hija' Al-Tanzil_li Abu Dawud Sulaiman Bin Al-Najah,
} jilid 2, h. 152.

\section{'A Jami Jurnal Bahasa dan Sastra Arab}


yā kedua pada surah al-Qalam (بأييكم) dibubuhi dengan tanda diakritik tasydid yang harus dibaca idgam karena bertemunya dua huruf yang sama.

Preferenasi Abū Dawud terkait dengan diakitik pada yā' ziyādah sebenarnya berpijak pada beberapa alasan, yakni: 1) Untuk kata (بأييد) ditujukkan agar terjadi perbedaan antara $y \bar{a}^{-}$asli dengan $y \bar{a}^{\varsigma}$ yang hanya berfungsi sebagai tambahan, 2) Untuk menunjukkan bahwa makna kata (بأييد) ditunjukkan pada makna (القوة) dan bukanlah bermakna tangan biasa yang merupakan bentuk mufrad-jamak dari kata (اليد - الأيدي). 3) Beliau juga memberi komentar bahwa cara beliau dalam menentukkan tanda diakritik pada yā' ziyādah merupakan pandangan gurunya (al-Dānī) yang dinilai bagus, 4) Persoalan yā' ziyādah berkaitan dengan وهذا ( masalah dua versi qira'ah, dan bacaan yang halus merupakan cara yang baik, (الوجه من الغامض اللطيف الحسن (ا) jika kata tersebut dibaca dengan cara tahqiq 40 maka sifrah (tanda kuning) diletakkan di atas alif, sedangkan ya dibiarkan kosong tanpa tanda diakritik, namun jika dibaca dengan cara tashi $1,{ }^{41}$ maka tanda diakritik pada ya dibubuhi dengan warna merah (الحمراء) dan membiarkan alif tanpa dibubuhi tanda diakritik apapun. ${ }^{42}$

Jika merujuk pada kitab beliau, sebenarnya banyak hal yang dibahas terkait preferensi dan kecenderungan pilihan beliau terkait tanda diakritik/ilmu al-ḍabt, namun karena tulisan ini diformat dalam bentuk jurnal ilmiah, maka penulis tidak mencantumkan semua pokok bahasan dan preferensi tersebut, dan hanya mengangkat masalah-masalah penting yang menjadi perdebatan ulama rasm dan dabt. Oleh karena itu penulis menyarankan pada peneliti lain untuk melanjutkan kajian-kajian semisal, mengingat belum banyaknya penelitian rasm dan dabt yang dikaji dari kitab-kitab klasik/turas

\section{Kesimpulan}

Abū Dawud Sulaiman bin Najah merupakan ulama al-Ḍabt wa al-Rasm berasal dari wilayah Magribi (Cordoba Andalusia) sangat diakui keluasan ilmunya, sehingga lewat dua karya monumetalnya: Ușūl al-ḍat wa kaifiyatuhu 'alā jihhah alIkhtișār, dan Mukhatașar al-Tabyīn li Hijă al-Tanzīl mayoritas negara-negara yang menyalin, mencetak dan memproduksi mushaf kebanyakan merujuk pada kedua kitab tersebut, terlebih lagi Mushaf Madinah yang dicetak oleh Mujamma' Malik al-Fah banyak men-tarjih pandangan Abū Dawud bila terjadi perbedaan dengan gurunya al-

${ }^{40}$ Tahqiq adalah bacaan dengan tingkatan pelan dan perlahan-lahan.

${ }^{41}$ Tashil ( تَسْيْيَّ ( ) berarti mudah, maksud bacaan tashil menurut ulama Qurra' adalah upaya memindahkan bacaan ayat-ayat al-Qur' an dengan cara memindahkan harakat atau membuang huruf tertentu, dengan tujuan agar lafaz tersebut tidak sukar diucapkan.

${ }^{42}$ Al-Tunisī, Al-Ṭirāz Fị Syarh Dabt Al-Kharrāz, h. 404.

\section{'A Jami Jurnal Bahasa dan Sastra Arab}


Dāni (مَعَ تَرْجِيْحِ الثَّانِي عِنْدَ أْلِخْتَلاَفِ). Inilah salah satu penyebab mengapa mushaf yang dicetak/disalin oleh berbagai negara memiliki perbedaan yang signifikan, baik pada tanda diaritik/al-dabt maupun pada rasm-nya, tidak lain disebabkan oleh keragaman rujukan yang diacu serta kecenderungan mana pandangan yang räjih dari yang marjūh untuk ditetapkan preferensinya.

Preferensi Abū Dāwūd secara umum dibahas pada lima belas bab, sedangkan secara khusus preferensi beliau pada penelitian ini nampak pada beberapa tanda diakritik: a) idgām al-nāqis pada kata (بَسَطَتَ - وأَحَطتُ - مَا فَرَّطتُمْمُ), menurutnya penulisannya mestinya tanpa dibubuhi harakat sukun karena huruf (b) memiliki sifat al-Itbaq yang berbeda dengan (ت), pendapat ini mengikuti pendapat gurunya al-Dāni,

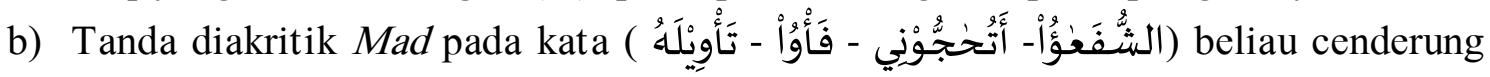
memilih pendapat menghilangkan huruf alif, wầ maupun yā' pada mad, c) Pada

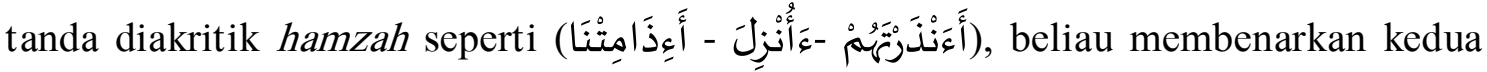
bentuk penulisan hamzah, sesuai dengan madzhab qirā'at al-kisā’i dan al-Farrā', d)

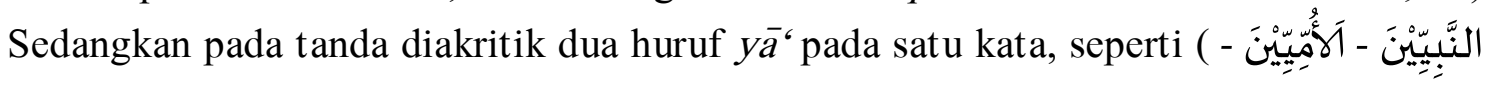
(رَنِنِيَّنْنَ Abu Dawud berbeda dengan pendapat gurunya al-Dani, dan memilih pendapat yang menurutnya lebih baik, yakni yā' jama' yang harus dibuang, karena $y \bar{a}$ ' tersebut hanyalah tambahan dan bukan akar kata, menurutnya jika yā' yang menjadi akar kata itu dibuang, akan menyebabkan rusaknya unsur keaslian kata, e) Tanda diakritik ziyādah yā', seperti pada kata (أَفإِين - نبإي) Abu Dawud memberi tanda lingkaran sebagai simbol bahwa huruf tersebut hanyalah ziyādahłambahan yang tidak dibaca, sedangkan tanda diakritik pada kata (بأييد) yang memiliki dua yā‘, Abū Dawud meletakkan tanda sukun pada $y \bar{a}$ ' pertama, sebagai pembeda antara yă aș $\bar{i}$ dan $y \bar{a}^{\bar{c}}$ zāidah, sedangkan pada $\overline{y a}$ kedua ditandai dengan lingkaran (الدائرة) sebagai penanda bahwa huruf tersebut merupakan ziyādah. Adapun untuk yā kedua pada surah alQalam (بأييكم) dibubuhi dengan tanda diakritik tasydid yang harus dibaca idgam karena bertemunya dua huruf yang sama.

\section{Daftar Pustaka}

Abū al-Qāsim bin Basyakwāl. Al-Ṣillah Fi Tarikh A'immah Al-Andalu'ihim Wa 'Ulamāihim Wa Muhaddisihim Wa Fuqahā'ihim Wa Udabā'ihim. Tunisia: Dār alGarb al-Islāmi, 2010.

Abū Dāwūd Sulaiman bin Najāh. Kitāb Ușūl Al-Ḍabt Wa Kaifiyatuhu 'ala Jihhah Al-

Ikhtisār. Edited by Ahmad bin Ahmad bin Mu'ammar Syirsyāl. al-Mamlakah al-

'Arabiyah al-Sa'udiyah: Mujamma' Malik al-Fahd li Tibā'ah Muṣhaf al-Syarif, 2010.

Ahmad, Jumal. "Desain Penelitian Analisis Isi (Content Analysis)." ResearchGate, no. June (2018): 1-20. https://www.researchgate.net/publication/325965331.

\section{'A Jami Jurnal Bahasa dan Sastra Arab}


Al-Amin, Salwa Ibraheem Tawfeeq. "The Origin of the Kufic Script.” Magazine of historical studies and archaeology دراسات في التاريخ والاثار, no. 53 (2016): 705-719.

Al-Buzgayah, Abu Bakar al-Siddiq bin Ibrahim. "Al-Imām Abū Dāwūd Sulaimān Bin Najjāh Wa Ikhtiyāratuhu Fi Rasm Al-Qur'āni.” Jami’ah al-Syahid Hammah alKhadar al-Wad, 2017.

Al-Dabbā', 'Ali Muhammad. Sāmir Al-Ṭālibīn Fī Rasm Wa Dabt Al-Kitāb Al-Mubīn. Edited by Abd al-Hamid Ahmad Al-Hanafi. 1st ed. Mesir, n.d.

Al-Dani, Abu Amar. Al-Muhkam Fi Naqt Al-Masahif. Edited by Izzah Hasan.

Damasqus, Suriah: Dar al-Fikr, 1986.

Al-Farmāwī, Abd Al-Hayy Husain. Rasm Al-Muš̄haf Wa Naqtuhu. Makkah: alMaktabah al-Makkiyah, 2004.

Al-Gāni, Abd al-Fattāḥ Abd. Tārikh Al-Muṣhaf Al-Syarîf. Kairo: Maktabah al-Jundi, 1972.

Al-Kafwìi, Abū Al-Baqā'. Al-Kulliyāt. Beirut: Mu'assasah al-Risālah, n.d.

Al-Quran, Lajnah Pentashihan Mushaf. Pedoman Penstahihan Mushaf Al-Quran. 1st ed. Jakarta, 2015.

Al-Tunisī, Muhammad bin 'Abdullah. Al-Ṭirāz Fị Syarh Dabt Al-Kharrāz. Tahqiq: Muhammad Syirsyāl. Madinah Munawwarah: Mujamma' Malik al-Fahd li Tibā'ah Muṣhaf al-Syarif, 2000.

Audah, Ali. Konkordansi Quran : Panduan Dalam Mencari Ayat Al-Quran. Litera Antar Nusa. Vol. 2. Bogor: Pustaka Lintera Antar Nusa, 1997.

Bahasa, Pusat. Kamus Bahasa Indonesia. Jakarta: Departemen Pendidikan Nasional, 2008.

Green, Samuel. "The Different Arabic Versions of the Qur'an.” Answering Islam. Last modified March 7 (2016).

Hula, Ibnu Rawandhy. "Genealogi Ortografi Arab (Sebuah Tinjauan Historis: AsalUsul, Rumpun Bahasa Dan Rekaman Inskripsi)." A Jamiy: Jurnal Bahasa dan Sastra Arab 9, no. 1 (2020): 16-46.

Isma'il, Sya'ban Muhammad. Rasm Al-Mushaf Wa Dabtuhu Baina Al-Tauqifi Wa AlIstilahat Al-Hadisah. Al-Qahirah: Dar al-Salam, 2012.

Madzkur, Zaenal Arifin. “Diskursus Ulumul-Qur'an Tentang Ilmu Dabth Dan Rasm Usmani; Kritik Atas Artikel Karakteristik Diakritik Mushaf Magribi, Arab Saudi Dan Indonesia.” SUHUF Jurnal Pengkajian Al-Qur'an dan Budaya 8, no. 2 (2015): 261-282.

Madzkur, Zainal Arifin. “Survei Bibligrafis Kajian Penulisan Al-Qur'an, Studi Literatur Rasm Usmani Dari Masa Klasik Sampai Modern.” ȘUHUF 12, no. Juni (2019): 151-170. https://jurnalsuhuf.kemenag.go.id/suhuf/issue/view/32.

Miolo, Damhuri Dj. Noor dan Muhtar. "Kontribusi Al-Khalil Bin Ahmad Al-Farahidi "A Jami Jurnal Bahasa dan Sastra Arab 
Dalam Ilmu-Ilmu Bahasa Arab.” Al-Lisan: Jurnal Bahasa 5, no. 2 (2019): 148160.

Muhammad Aqib Mayabi al-Junki al-Syinqiti. Nazam Rasyf Al-Lama 'ala Kasyf Al'Ama. Omman: Dar al-Iylaf al-Dauliyah, 2012.

Mujamma' Malik al-Fahd li Tiba'ah al-Mushaf al-Syarif. "Mushaf Al-Madinah AlMunawarah Li Al-Nasyr Al-Hasubi." Al-Madinah Al-Munawwarah. Last modified 2015. https://books-library.online/free-124029141-download. Najah, Abu Dawud Sulaiman bin. Mukhtasar Al-Tabyin Li Hija'Al-Tanzil_li Abu Dawud Sulaiman Bin Al-Najah. Edited by . Aḥmad bin Aḥmad bin Mu'ammār Syirsyāl. Al-Madinah al-Munawwarah: Maktabah Mālik al-Fahd, 2002.

—. Uṣūl Al-Ḍabt Wa Kaifiayatuhū Ala Jihhah Al-Ikhatiṣār. Madinah

Munawwarah: Mujamma' Malik al-Fahd li Tibā'ah Muṣhaf al-Syarif, 2006.

Porteus, John Douglas. Environment and Behavior Planning and Everyday Urban Life. Boston: Addison-Wesley, 1997.

Rahman, Abd. "Perbandingan Rasm Usmani Antara Mushaf Standar Indonesia Dan Mushaf Pakistan Perspektif Al-Dānī 'Analisis Kaidah Hażf Al-Harf Dalam Rasm Usmani,", 2018.

Rohmah, Hajar Nur. Kajian Rasm Mushaf (Perbandingan Antara Mushaf Standar Indonesia Dan Mushaf Maroko). IAIN SALATIGA, 2020.

Sālim bin 'Abdullāh bin Muhammad al-Zahrānī. Dabt Al-Qur'an Al-Karim:

Nasy'atuhu, Wa Ta Tawwuruhu, Wa “Ināyah Al-'Ulama” Bihi. Makkah alMukarramah: Jami'ah Umm al-Qurā, n.d.

Syaniy, Falih Khadir. “'اللحن الخفيّ : مظاهره، وطرائق اجتنابه دراسة في ضوء رياضة الألسن عند القرًاء. Wasit

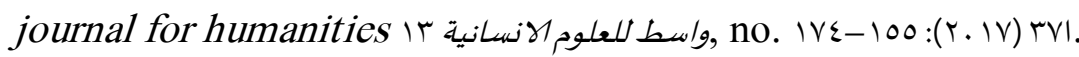

Thobroni, Ahmad Yusam. "Ibnu Mujahid Dan Konstribusinya Dalam Qira'at AlQur'an.” Al-Fikra: Jurnal Ilmiah Keislaman 7, no. 1 (2017): 63-79.

Wahyudi, Rudi. "Perbandingan Mushaf Al-Qur'an Standar Utsmani Indonesia Dan Saudi Arabia" (2018).

Wikipedia. “Arab Magrib.” The Columbia Encyclopedia. Last modified 2001. http://www.north-africa.com/.

_. "Arab Masyriq." Britannica.Com/Place/Mashriq. Last modified 2019. https://id.wikipedia.org/wiki/Arab_Masyriq.

Yazid, Hisyami bin. Risālah Fì 'Ilmi Ḍabt Al-Qur'ān Li Hal Al-Musykilah Al-Hadisah Mā Fï Rasm Al-Mushafi Al- 'Ușmānī. Banda Aceh: Ar-Rijal Publisher, 2012.

\section{'A Jami Jurnal Bahasa dan Sastra Arab}

